\title{
Role of Special Olympics for Mothers of Adult Athletes With Intellectual Disability
}

\author{
Jonathan A. Weiss \\ Centre for Addiction for Mental Health, Dual Diagnosis Program (Toronto)
}

\begin{abstract}
The role of Special Olympics in the lives of mothers of adult athletes was examined. Fortysix mothers participated in a longitudinal study, completing a parenting stress questionnaire, a measure of their child's maladaptive behavior, and a survey of athlete involvement in Special Olympics at two time periods, 42 months apart. Results confirm that involvement in Special Olympics is negatively correlated with mothers' role restriction, isolation, depression, and problems with competence and attachment. Involvement in Special Olympics fully mediated the effect of child social maladjustment on maternal role restriction and depression and partially mediated its effect on maternal problems with competence. Taken together, these findings suggest that Special Olympics can function as a formal support for mothers.
\end{abstract}

The parental experience of having a child with an intellectual disability has long been a topic of research. Researchers have reported that raising a child with an intellectual disability can increase the distress experienced by mothers (Crnic, Friedrich, \& Greenberg, 1983) and fathers (Bristol, Gallagher, \& Schopler, 1988). At the same time, authors have stressed that the experience of having a child with an intellectual disability is not always negative (Flaherty \& Glidden, 2000; Hassall \& Rose, 2005; Saloviita, Italinna, \& Leinonen, 2003). It is clear that parent functioning is the result of multiple factors that mediate and moderate the effect of stressors (see Hassall \& Rose, 2005; Perry, 2005, for review of various models). In the present study I examined the relations among a child-related stressor, a mediating variable, and the functioning of mothers of adult children with intellectual disabilities. Because most of these individuals are supported by their family throughout their life (Orsmond, Seltzer, Krauss, \& Hong, 2003), parenting becomes a lifelong activity (Glidden \& Schoolcraft, 2003), and the study of the experiences of parents with adult children with intellectual disabilities is highly relevant.
Parent functioning across the lifespan has been shown to be affected by two classes of stressors: those related to the child and those related to parent characteristics and the environment. Earlier researchers have operationalized stressors in a number of ways, including the nature and severity of a child's disability, temperament (Krauss, 1993), caretaking demands (Minnes, 1988), and maladaptive behavior (internalizing and externalizing problem behavior) (Hodapp, Dykens, \& Masino, 1997). Investigators have also examined stressors related to caregiver variables, such as education, financial resources, health, and parent age (Hauser-Cram, Warfield, Shonkoff, \& Krauss, 2001; Minnes \& Woodford, 2005).

Investigators have identified a number of important factors that can act as buffers to the impact of stressors on parent functioning. Potential mediators include social support (Kazak, 1987), perceived parent self-efficacy (Pakenham, Sofronoff, \& Samios, 2004), ability to perform cognitive reframing (Minnes \& Woodford, 2005), marital adjustment and level of spousal support (Saloviita et al., 2003), caregiver personality (Baker, Blacher, \& Olsson, 2005), and coping strategies (Bristol, 
1987). Formal supports have also been recognized as having the potential to play a role in supporting clients and families (Keller \& Honig, 2004), and unmet service needs has been shown to be a negative predictor of caregiver well-being (Seltzer \& Krauss, 1989). Formal supports can be defined as the quantity and quality of professional and paraprofessional interventions, including counseling, support groups, and educational/treatment programs (Perry, 2005).

Despite the number of researchers who have examined the link between physical activity programs, such as Special Olympics and psychosocial variables of the athlete (Castagno, 2001; Dykens \& Cohen, 1996; Gibbons \& Bushakra, 1989; Riggen \& Ulrich, 1993; Weiss, Diamond, Demark, \& Lovald, 2003), few authors have tested whether these programs can act as a form of support for parents. What is known is that the majority of parents of Special Olympics athletes believe that the organization is beneficial in promoting life satisfaction and social adjustment of their child and that it enhances levels of family support, involvement, and cohesiveness (Klein, Gilman, \& Zigler, 1993). As mentioned earlier, the degree of child problem behavior has been found to be one of the greatest factors leading to increased levels of parental stress (Krauss, 1993). Because involvement in Special Olympics has been shown to be negatively correlated with maladaptive behavior in participants (Gencoz, 1997) and positively associated with competence (Dykens \& Cohen, 1996), in the current study I examined the role that Special Olympics may play in mediating the relation between child behavior problems and parent functioning.

Just as the types of stressors and mediating variables differ from one study to another, so does the operationalization of parent functioning (Perry, 2005). Several researchers have discussed outcome in terms of stress, as measured by questionnaires such as the Parenting Stress Index (Abidin, 1995) or a short form of the Questionnaire on Resources and Stress (Friedrich, Greenberg, \& Crnic, 1983). In turn, stress is often deconstructed into a variety of separate, yet interrelated constructs, such as isolation, depression, and relationship conflict (Hanson \& Hanline, 1990), parent well-being (Hauser-Cram et al., 2001), financial stress, lack of parent reinforcement, and family disharmony (Jones \& Passey, 2005), or quality of parenting (Bristol, 1987). Most investigators have sought to conceptualize outcome in a way that answers questions regarding the parent experience, whether it be measured by affective, cognitive, or interpersonal factors. In the present study I have conceptualized parent functioning by using a number of parent-related subscales of the Parenting Stress Index: Depression, Role Restriction, Social Isolation, and Problems With Competence and Attachment.

Using the mediation model test outlined by Baron and Kenny (1986), I examined whether a child's involvement in the Special Olympics program can mediate the relation between child maladaptive behavior and parent functioning. I used a Time 1-Time 2 repeated measures design to assess the predictive capability of athlete involvement in Special Olympics at Time 1 on parent functioning 42 months later. A number of conditions must be satisfied to test a mediation model. Initially, a relation must exist between the predictor variable and the outcome variable, as illustrated in Figure 1 (Panel A). This represents the first hypothesis: Children's maladaptive behavior

Panel A
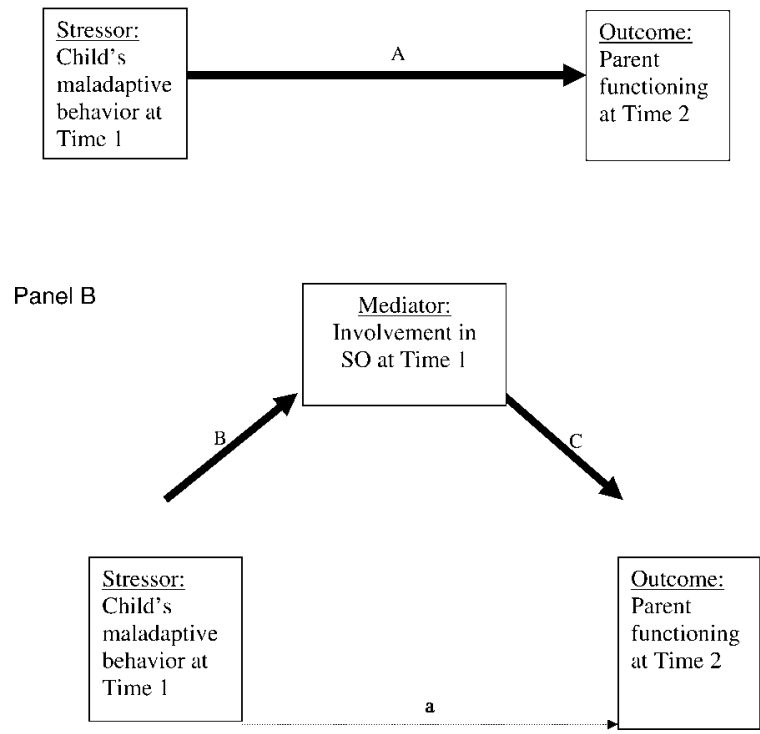

Figure 1. Panel A illustrates the initial hypothesis that the stressor at Time 1 will be predictive of parent functioning at Time 2 (Path A). Panel B illustrates the hypotheses that the stressor will be related to the mediator (Path $\mathrm{B}$ ), and that the mediator at Time 1 will be predictive of outcome at Time 2 (Path $\mathrm{C}$ ), accounting for the initial variance linking the stressor to outcome (Path a). SO $=$ Special Olympics. 
at Time 1 will predict parent functioning at Time 2. Second, a relation must exist among the predictor variable and the mediator (see Figure 1, Panel B, Path B). My hypothesis was that children's maladaptive behavior at Time 1 will be related to their degree of involvement in Special Olympics at Time 1 (Path B). Finally, the mediator must be related to the outcome (Path $C$ ) in such a way that the impact of the initial predictor variable on the outcome variable is lessened when the mediator is included in the model. This constitutes the third and fourth hypotheses: that involvement in Special Olympics at Time 1 will be predictive of parent functioning at Time 2 and that involvement in Special Olympics will mediate the impact of children's maladaptive behavior at Time 1 on parent functioning at Time 2. A complete mediation occurs when the relation between the initial variable and the outcome (Path A) becomes zero after the inclusion of the mediator.

\section{Method}

\section{Participants at Time 1}

The original sample at Time 1 was comprised of 70 mothers who completed the parent outcome measure, out of a total of 94 families who were participants in a larger survey of Special Olympics involvement. There were no differences in terms of family income, educational level, involvement in Special Olympics, child maladaptive behavior, or IQ between mothers who completed the parent outcome measure at Time $1(n=70)$ and those who did not $(n=24)$.

Mothers ranged in age from 35.0 to 76.0 years $(M=55.4, S D=10.2)$ and had a mean of 3 children $(S D=.29)$. Seventy-five percent of mothers identified themselves as Caucasian, 6\% as First Nations, 2\% as Asian Canadian, and 2\% as African Canadian. Fifteen percent of mothers chose not to indicate their ethnicity. In terms of highest level of academic achievement, 24\% of mothers did not complete high school, $36 \%$ graduated high school, $37 \%$ graduated college or university, and 3\% completed a postgraduate degree. Sixteen percent of mothers reported a family income of less than $\$ 20,000$ per year, $14 \%$ between $\$ 20,000$ and $\$ 40,000,36 \%$ between $\$ 40,000$ and $\$ 60,000,22 \%$ between $\$ 60,000$ and $\$ 80,000$, and $12 \%$ over $\$ 80,000$.

The average age of athletes was 28.5 years ( $S D$ $=8.15$, range $=17.6$ to 42.5$)$, and their average
IQ was $55.6(S D=14.9$, range $=40$ to 90$)$. Ninety-one percent of athletes lived at home; 6\%, group homes; and 3\%, independently. Thirty-six percent of children had Down syndrome; 32\%, unknown cause of intellectual disabilities; $4 \%$, autism; $6 \%$, cerebral palsy; and $4 \%$, fragile $\mathrm{X}$ syndrome. The remaining $18 \%$ were classified as "Organic Specified Other," which included rarer causes of intellectual disabilities (i.e., Williams syndrome or Sotos syndrome), and brain damage.

\section{Participants at Time 2}

Because of failure to locate, refusals, and deaths, a number of mothers did not complete the follow-up data collection (i.e., nonresponders); however, 46 families agreed to participate in the follow-up assessment, a $66 \%$ participation rate. I calculated $t$ tests and chi-square tests on Time 1 demographic variables and involvement in Special Olympics, comparing responding and nonresponding mothers. The two groups of mothers did not differ on parent age, child IQ, number of sports, number of hours per week in training, number of competitions, degree of child maladaptive behavior, parent health, and parent functioning (see Table 1). Responding mothers had children who were involved in Special Olympics for more years than did mothers who were nonresponders at Time $1, t(69)=2.58, p=.01$, and obtained more medals and ribbons than nonresponders, $t(69)=2.57, p=.01$. Although groups did not statistically differ in formal education or reported family income, a disproportionate amount of nonresponding mothers did not graduate high school (33\% vs. 16\%), did not have a college degree (36\% vs. $17 \%)$, and reported a family income of under $\$ 20,000$ per year $(23.4 \%$ vs. $8.9 \%)$.

\section{Measures}

Demographic information. I constructed a demographic questionnaire to elicit information regarding child (e.g., age, gender, type of disability), mother (e.g., age), and family characteristics (e.g., socioeconomic status, family educational background, ethnicity).

IQ. Participants' cognitive abilities were assessed at Time 1 on the Kaufman Brief Intelligence Test-K-BIT (Kaufman \& Kaufman, 1990). This instrument is an individually administered screener of verbal and nonverbal intelligence. Internal consistency reliabilities average .94 for the 
Table 1. Characteristics of Responding and Nonresponding Mothers

\begin{tabular}{|c|c|c|c|c|}
\hline \multirow[b]{2}{*}{ Characteristic } & \multicolumn{2}{|c|}{ Responders $(n=46)$} & \multicolumn{2}{|c|}{ Nonresponders $(n=24)$} \\
\hline & Mean $/ \%^{a}$ & $S D$ & Mean $/ \%^{a}$ & $S D$ \\
\hline \multicolumn{5}{|l|}{ Athlete } \\
\hline Age (years) & 26.02 & 8.00 & 22.78 & 8.57 \\
\hline IQ & 53.29 & 12.32 & 57.86 & 15.07 \\
\hline No. of sports & 3.53 & 1.77 & 3.10 & 1.79 \\
\hline No. of hours per week & 3.72 & 2.40 & 4.61 & 2.49 \\
\hline No. of years & 11.25 & 7.67 & 7.87 & 5.23 \\
\hline No. of total competitions & 43.03 & 44.22 & 28.66 & 47.33 \\
\hline No. of medals and ribbons & 82.67 & 139.49 & 17.52 & 19.74 \\
\hline \multicolumn{5}{|l|}{ Parent } \\
\hline Age (years) & 54.27 & 9.07 & 51.51 & 10.81 \\
\hline \multicolumn{5}{|l|}{ Education level (\%) } \\
\hline Did not graduate high school & 15.6 & - & 33.3 & - \\
\hline Graduated high school & 35.6 & - & 35.4 & - \\
\hline Graduated college & 35.6 & - & 16.7 & - \\
\hline Graduated university/professional school & 13.3 & - & 14.6 & - \\
\hline \multicolumn{5}{|l|}{ Family income (in thousands, \%) } \\
\hline$<20$ & 8.9 & - & 23.4 & - \\
\hline 20 to 40 & 17.8 & - & 10.6 & - \\
\hline 41 to 60 & 37.8 & - & 34.0 & - \\
\hline 61 to 80 & 24.4 & - & 19.1 & - \\
\hline$>80$ & 11.1 & - & 12.8 & - \\
\hline Child social maladjustment & 102.86 & 9.53 & 100.61 & 10.77 \\
\hline \multicolumn{5}{|l|}{ Maternal } \\
\hline Competence & 29.00 & 6.92 & 28.32 & 6.22 \\
\hline Isolation & 11.95 & 5.09 & 12.41 & 3.97 \\
\hline Attachment & 11.93 & 3.92 & 11.39 & 2.86 \\
\hline Role restriction & 15.15 & 5.13 & 15.91 & 4.81 \\
\hline Depression & 18.20 & 5.08 & 17.78 & 5.60 \\
\hline
\end{tabular}

${ }^{a}$ Means unless otherwise noted.

overall K-BIT IQ Composite, .93 for the Vocabulary subtest, and .88 for the Matrices subtest. Test-retest reliabilities are also strong (Vocabulary, .86 to .97 ; Matrices, .80 to .92 ; and IQ Composite, .92 to .95$)$.

Stressor variable: Social maladjustment. Maladaptive behavior was assessed by the Social Adjustment factor of the Adaptive Behavior ScalesResidential and Community Edition, Second Edition-ABS-RC2 (Nihira, Leland, \& Lambert, 1993). The Social Adjustment factor measures aggressive, antisocial, and inappropriate interpersonal behavior. Individuals who score low on this scale often act out, are rebellious, and are unpredictable in their relationships (i.e., have poor social adjustment), and higher scores on the social adjustment factor are indicative of less maladaptive behavior. Because my rationale in the current study is based on the exhibition of maladaptive behavior, I reversed items on this scale in order to reflect social maladjustment. For clarity, in the Results and Discussion sections, I refer to this measure as social maladjustment.

The ABS-RC2 was standardized on 4,000 individuals with intellectual disabilities who ranged in age from 18 to over 60 years. The standard age- 
related norms were used to determine standard scores in order to compare individuals of different ages. The Social Adjustment factor demonstrates good test-retest reliability, $r=.98$, and internal consistency, Cronbach $\alpha=.96$. Concurrent validity ratings are also high. The ABS-RC2 possesses a second maladaptive factor, Personal Adjustment, which reflects behaviors that are stereotyped and maladaptive but not antisocial or aggressive towards others. Because aggression is a main reason for adults with intellectual disabilities to be referred to mental health services and a significant cause for caregiver concern (Addington, Addington, \& Ens, 1993; Hurley, Folstein, \& Lam, 2003), and because there has been some indication that externalizing behaviors may be more stressful for mothers of children with intellectual disabilities compared to internalizing problems (Margalit, Shulman, \& Stuchiner, 1989), only the Social Maladjustment measure was included in the present study.

Mediator variable: Involvement in Special Olympics. A child's involvement in Special Olympics was assessed by parent completion of a questionnaire about the number of (a) years that their child was involved in Special Olympics, (b) medals and ribbons obtained, (c) competitions attended, (d) sports, and (e) hours per week in training.

Outcome variables: Parent functioning. I assessed parent functioning using subscales of the ParentRelated domain of the Parenting Stress Index, Third Edition (Abidin, 1995). Although this measure contains both Child-Related and Parent-Related domains, a number of authors have suggested that only the more parent-related factors of commonly used parenting stress measures represent outcome, whereas child-related factors are more indicative of stressors (Perry, 2005; Saloviita et al., 2003). I used five subscales: Problems With Competence, Isolation, Attachment, Role Restriction, and Depression. Higher scores reflect increasing dysfunction or potential experience of stress. High scores on Problems With Competence reflect problems with perceived parenting competence, such as "I can't make decisions without help." High scores on Isolation indicate that parents are socially isolated and lack emotional support systems and would endorse statements such as "I feel alone and without friends." High scores on the Attachment subscale reflect a lack of emotional closeness with the child, found in statements such as "It takes a long time for parents to develop close, warm feelings for their chil- dren.” A high score on Role Restriction suggests agreement with statements such as "I find myself giving up more of my life to meet my children's needs than I ever expected." The Depression subscale measures feelings of sadness as well as guilt and unhappy feelings towards the child, found in statements such as "I feel every time my child does something wrong it is really my fault," and high scores can reflect clinical depression or dissatisfaction with self and life circumstances.

The Parenting Stress Index:3 is a 120-item questionnaire commonly used to measure stress within families of children with intellectual disabilities. Questions are answered by the parent on a Likert-type scale ranging from strongly agree to strongly disagree with reference to the current situation. The Parent-Related domain has good testretest reliability, $r s=.69$ to .91 , internal consistency, Coefficient $\alpha=.93$, and is one of the most widely used measures of parenting stress in the literature. In the present study I assessed parents of individuals beyond the usual age range of the instrument (birth to 12 years). With permission, I adapted and pilot tested the Parenting Stress Index:3 to determine its appropriateness for an older age group, making minor modifications to the item language. Cronbach $\alpha$ for the Parenting Stress Index Parent-Related domain was .90 (subscales range $=.68$ to .83$)$, similar to the normative data (Abidin, 1995).

\section{Procedure}

As part of a larger prospective study of involvement in Special Olympics, I initially solicited athletes and their parents by telephone and letter through regional Special Olympics chapters across Ontario in 2001, with testing completed for Time 1 in May 2002. After informed consent was explained to parents and athletes over the telephone, families that agreed to participate were mailed a copy of the Parenting Stress Index:3, ABS-RC2, demographic questionnaire, and the involvement in Special Olympics questionnaire. When parents returned the signed consent forms and the questionnaire packages, athletes met individually with a researcher, who used the K-BIT for interviewing them. In August 2004, families who participated in the initial project and who gave their consent to be contacted again for future projects were asked to participate in the followup. All families who participated in Time 1 consented to being contacted again and were mailed the same set of questionnaires. A mean of 42 
months $(S D=.42)$ passed between parents' completion of the questionnaires at Times 1 and 2 . All athletes continued their Special Olympics involvement between Times 1 and 2, and there were no atypical interruptions over this time period.

\section{Results}

Child social maladjustment and parent functioning at Time 1 and Time 2 are presented in Table 2. Child Social Maladjustment scores were compared to ABS-RC2 norms to determine the percentage of the current sample of athletes with clinically significant social maladjustment. Although beyond the age-related norms, Parenting Stress Index subscale scores were compared to the normative Parenting Stress Index clinical profile to estimate the percentage of mothers with clinically significant levels of stress. No athletes were functioning $2 S D$ s above the ABS-RC2 mean. At Time $1,5 \%$ to $16 \%$ of mothers reported clinically significant stress at least $2 S D$ s above the mean, depending on the subscale. Similar levels were noted for Time 2 scores.

\section{Special Olympics Summary Variable}

Because there were substantial intercorrelations among Special Olympics components, I constructed a summary variable reflecting involvement in Special Olympics. Raw scores were transformed into $T$ scores with a mean of 50 and $S D$ of 10 . I calculated an average of these standard scores to reflect an athlete's overall degree of involvement. Mean involvement in Special Olympics was found to be correlated to number of years in program, $r=.70, p<.001$, medals and ribbons, $r=.78, p<.001$, competitions, $r=.73$, $p$ $<.001$, hours, $r=.65, p<.001$, and sports played, $r=.65, p<.001$, indicating that the summary variable reflects the individual components well.

\section{Control Variables}

Recently, researchers have reported differences in stress for parents of children with Down syndrome compared with mothers of children who had other causes of intellectual disabilities (Ricci \& Hodapp, 2003). Therefore, the child's diagnosis was given a dummy value (coded as Down syndrome vs. no Down syndrome) and was treated as a control in all analyses. Because parent age has also been linked to parent adjustment (Minnes \& Woodford, 2005), it was also treated as a control variable. For each analysis, the relevant Time 1 parent functioning variable was also forced into the model to control for baseline levels (e.g., controlling for Time 1 parent competence when testing the relation among Time 1 stressor and Time 2 parent competence). No cases obtained significant Mahalanobis distance using a criterion of $p$ less than .01. I examined colinearity diagnostics at every regression step and found no variance proportions to demonstrate multicolinearity.

\section{Test of Mediation}

I conducted multiple regression analyses for each Parenting Stress Index:3 subscale to test the hypothesized mediation model (see Baron \& Kenny, 1986), which involved three steps.

Step 1: Social maladjustment and maternal stress. In Step 1, regressions were calculated to establish the relation between social maladjustment (i.e., the stressor) at Time 1 and each maternal outcome variable at Time 2. Child diagnosis, parent age, and the relevant baseline (Time 1) Parenting Stress Index:3 score were entered as control vari-

Table 2. Mean Athlete Social Maladjustment and Maternal Stress Scores by Time

\begin{tabular}{lccccccc}
\hline & \multicolumn{3}{c}{ Time 1 } & & \multicolumn{3}{c}{ Time 2 } \\
\cline { 2 - 5 } \cline { 6 - 8 } Variable & Mean & SD & >2 SD (\%) & & Mean & SD & >2 SD (\%) \\
\hline Athlete social maladjustment & 102.86 & 9.53 & 0 & & 104.34 & 8.10 & 0 \\
Maternal & & & & & & & \\
$\quad$ Competence & 29.00 & 6.92 & 13 & & 28.02 & 6.39 & 10 \\
Isolation & 11.95 & 5.09 & 16 & & 11.51 & 4.86 & 12 \\
$\quad$ Attachment & 11.93 & 3.92 & 13 & & 11.91 & 3.44 & 12 \\
$\quad$ Role restriction & 15.15 & 5.13 & 5 & & 13.98 & 5.43 & 5 \\
$\quad$ Depression & 18.21 & 5.09 & 5 & & 17.23 & 4.92 & 4 \\
\hline
\end{tabular}


ables. As shown in Table 3 (Step 1), social maladjustment emerged as a significant predictor of four out of five maternal stress domains and accounted for $7 \%$ to $16 \%$ unique variance. The initial regression failed to find a significant relation between social maladjustment and problems with maternal attachment.

Child diagnosis was found to be a significant predictor of maternal role restriction, isolation, and problems with attachment; it accounted for $6 \%$ to $10 \%$ unique variance. In each case, mothers of children with Down syndrome reported less severe problems than mothers of comparison group children with other causes of intellectual disabilities, after taking the other predictors into account. Independent sample $t$ tests were calculated to assess whether differences in maternal stress levels were significant at a univariate level. There was no

Table 3. Standard Multiple Regression of Social Maladjustment and Special Olympics Involvement on Maternal Outcomes

\begin{tabular}{|c|c|c|c|c|c|c|}
\hline \multirow{2}{*}{$\begin{array}{l}\text { Maternal outcome/ } \\
\text { Predictor variable }\end{array}$} & \multicolumn{2}{|c|}{ Step 1} & \multicolumn{2}{|c|}{$\begin{array}{c}\text { Step } 2 \\
\text { (DV: SO involvement) }^{a}\end{array}$} & \multicolumn{2}{|c|}{ Step 3} \\
\hline & $\beta$ & $t$ & $\beta$ & $t$ & $\beta$ & $t$ \\
\hline \multicolumn{7}{|l|}{$\begin{array}{l}\text { Problems with } \\
\text { competence }\end{array}$} \\
\hline $\begin{array}{l}\text { Diagnosis } \\
\text { Age } \\
\text { T1 competence } \\
\text { Maladjustment } \\
\text { SO involvement }{ }^{\mathrm{b}}\end{array}$ & $\begin{array}{r}-.08 \\
.13 \\
.57 \\
.39 \\
\\
R=.80 \\
\end{array}$ & $\begin{array}{l}-.76 \\
1.13 \\
4.76^{* * *} \\
3.22^{* *} \\
\text { dj. } R^{2}=.61\end{array}$ & $\begin{array}{r}-.31 \\
.57 \\
-.11 \\
-.25 \\
\\
R=.76 \\
\end{array}$ & $\begin{array}{c}-3.02^{* *} \\
5.26^{* * *} \\
-.94 \\
-2.14^{*} \\
\text { dj. } R^{2}=.53\end{array}$ & $\begin{array}{c}-.02 \\
-.04 \\
.73 \\
.29 \\
-.36 \\
R=.9 \\
\end{array}$ & $\begin{array}{c}-.18 \\
-.31 \\
6.33 * * * \\
2.52 * \\
-2.71 * * \\
\text { dj. } R^{2}=.78 \\
\end{array}$ \\
\hline \multicolumn{7}{|l|}{ Role restriction } \\
\hline $\begin{array}{l}\text { Diagnosis } \\
\text { Age } \\
\text { T1 restriction } \\
\text { Maladjustment } \\
\text { SO involvement }{ }^{\mathrm{b}}\end{array}$ & $\begin{array}{r}-.33 \\
-.05 \\
.46 \\
.44 \\
\\
R=.74 \\
\end{array}$ & $\begin{array}{l}-2.93 * * \\
-.46 \\
4.07 * * * \\
3.83 * * * \\
\text { dj. } R^{2}=.50\end{array}$ & $\begin{array}{r}-.29 \\
.57 \\
-.17 \\
-.26 \\
\\
R=.7 \\
\end{array}$ & $\begin{array}{l}-3.04 * * \\
5.81 * * * \\
-1.71 \\
-2.63 * * \\
\text { dj. } R^{2}=.59\end{array}$ & $\begin{array}{c}-.63 \\
-.32 \\
.33 \\
.20 \\
-.78 \\
R=.8 \\
\end{array}$ & $\begin{array}{c}-4.62 * * * \\
-2.05^{*} \\
2.74 * * \\
1.45 \\
-3.80^{* *} \\
\text { idj. } R^{2}=.69 \\
\end{array}$ \\
\hline \multicolumn{7}{|l|}{ Depression } \\
\hline $\begin{array}{l}\text { Diagnosis } \\
\text { Age } \\
\text { T1 depression } \\
\text { Maladjustment } \\
\text { SO involvement }{ }^{\mathrm{b}}\end{array}$ & $\begin{array}{r}-.15 \\
.01 \\
.43 \\
.35 \\
\\
R=.68 \\
\end{array}$ & $\begin{array}{c}-1.22 \\
.08 \\
3.06 * * \\
2.40^{*} \\
\\
\text { dj. } R^{2}=.40\end{array}$ & $\begin{array}{r}-.31 \\
.57 \\
-.10 \\
-.25 \\
R=.7 \\
\end{array}$ & $\begin{array}{c}-3.15^{* *} \\
5.65^{* * *} \\
-.91 \\
-2.15^{\star} \\
\text { dj. } R^{2}=.57\end{array}$ & $\begin{array}{c}-.57 \\
.38 \\
.39 \\
.004 \\
-.83 \\
R=.8 \\
\end{array}$ & $\begin{array}{c}-3.58^{* *} \\
2.04^{*} \\
2.53^{*} \\
.03 \\
-3.56 * * \\
\text { dj. } R^{2}=.57 \\
\end{array}$ \\
\hline \multicolumn{7}{|l|}{ Isolation } \\
\hline $\begin{array}{l}\text { Diagnosis } \\
\text { Age } \\
\text { T1 Isolation } \\
\text { Maladjustment } \\
\text { SO involvement }\end{array}$ & $\begin{array}{r}-.25 \\
-.07 \\
.80 \\
.26 \\
R=.87\end{array}$ & $\begin{array}{l}-2.96^{* *} \\
-.86 \\
9.42^{* * *} \\
2.75^{* *} \\
\\
R^{2}=.73\end{array}$ & $\begin{array}{r}-.28 \\
.58 \\
-.19 \\
-.26 \\
R=.8\end{array}$ & $\begin{array}{l}-2.86 * * \\
5.92 * * * \\
-1.89 \\
-2.66 * * \\
\text { dj. } R^{2}=.60\end{array}$ & $\begin{array}{r}-.24 \\
-.17 \\
.79 \\
.27 \\
-.30 \\
R=.8\end{array}$ & $\begin{array}{l}-2.42^{*} \\
-1.56 \\
8.50^{* * *} \\
3.20^{* *} \\
-2.60^{*} \\
\text { dj. } R^{2}=.75\end{array}$ \\
\hline
\end{tabular}

${ }^{a} \mathrm{DV}=$ dependent variable, $\mathrm{SO}=$ Special Olympics. ${ }^{\mathrm{b}}$ Not included in Steps 1 and 2.

${ }^{*} p<.05 .{ }^{* * p}<.01 .{ }^{* * *} p<.001$.

(C) American Association on Intellectual and Developmental Disabilities 
significant difference between groups in role restriction, isolation, or problems with attachment. Parent age was not related to any parent-stress domain.

Step 2: Social maladjustment and involvement in Special Olympics. A second set of multiple regressions were calculated to establish the relation between the predictor variable, social maladjustment, and the Special Olympics mediator variable. Again, I entered parent age, child diagnosis, and the relevant baseline Parenting Stress Index score as control variables. As shown in Table 3 (Step 2), in all cases social maladjustment was found to be a significant predictor of involvement in Special Olympics, accounting for 5\% to 6\% unique variance. The greater an athlete's social maladjustment, the less involvement they tended to have in Special Olympics. Parent age was a stronger predictor of involvement in Special Olympics, accounting for $28 \%$ to $45 \%$ unique variance. Child diagnosis was also predictive of involvement in Special Olympics, with children who had Down syndrome involved to a greater degree compared with children who had other etiologies, after taking the other predictors into account. However, this difference was not significant when tested with an independent samples $t$ test.

Step 3: Social maladjustment, involvement in Special Olympics, and maternal stress. After taking into account social maladjustment, I used a third set of multiple regressions to assess the relation among the mediator variable, involvement in Special Olympics, and maternal outcome at Time 2. Social maladjustment and Special Olympics involvement were entered as predictors of each of the maternal outcomes, after including the control variables. The overall models were significant in predicting problems with competence, $F(5,30)$ $=15.82, p<.001$ (78\% adjusted variance), role restriction, $F(5,34)=11.88, p<.001(69 \%$ adjusted variance), depression, $F(5,34)=7.45, p<$ .001 (57\% adjusted variance), and isolation, $F(5,34)=20.65, p<.001(75 \%$ adjusted variance). As shown in Table 3, Special Olympics was found to be a significant independent predictor of each of the maternal outcome variables and accounted for $5 \%$ to $23 \%$ unique variance. Although social maladjustment was not related to problems with maternal attachment (Step 1), a similar regression revealed that involvement in Special Olympics was a significant predictor of attachment difficulties, $t(41)=-2.39, p=.03$, ac- counting for 13\% unique variance, in an overall significant model, $F(5,34)=4.33, p<.001(34 \%$ adjusted variance).

The third step of multiple regression analyses was also used to test whether Special Olympics involvement was a partial or complete mediator, in such a way that its inclusion into the regression model lessens the impact of social maladjustment on parent functioning. I examined differences between the stressor's Step 1 and Step 3 standardized beta coefficients as well as changes in the amount of unique variance attributed to social maladjustment. If a decrease was observed, then I used the web-based Sobel test to assess whether involvement in Special Olympics carried significant weight linking social maladjustment to maternal outcomes (Preacher \& Leonardelli, 2001).

Changes in the impact of social maladjustment were observed in the hypothesized direction with regard to maternal problems with competence, role restriction, and depression. As shown in Table 3, social maladjustment remained a significant predictor of mothers' problems with competence in Step 3 and accounted for 7\% unique variance. The beta coefficient linking social maladjustment to maternal competence decreased from .39 (Step 1) to .29 (Step 3). The Sobel test did not support the hypothesis of a full mediator. The beta coefficient linking social maladjustment to maternal role restriction decreased from $.45, p$ $<.001$, to $.20, p=.16$, and the Sobel test confirmed that Special Olympics is a significant mediator, Test statistic $=2.16, p=.03$. The beta coefficient for child diagnosis was found to increase with the inclusion of the Special Olympics variable, from -.33 to -.63 . Similarly, the beta coefficient linking social maladjustment to maternal depression decreased from $.34, p=.02$, to $.004, p=.98$, suggesting that Special Olympics functions as a full mediator, supported by the Sobel test, Test statistic $=1.92, p=.05$. At the same time, the variance explained by child diagnosis increased from $3 \%$ to $18 \%$, with the insertion of the Special Olympics variable. Contrary to expectations, the beta coefficient linking social maladjustment to maternal isolation remained unchanged, failing to support the hypothesis that Special Olympics acts as a mediator between stressor and maternal isolation.

\section{Discussion}

Results of this study widen the focus of empirical research on the effects of physical activity 
programming, from the individual athlete to the family. The model specified that the effect of a child's maladaptive behavior would act as a stressor on parenting functioning and that its effect could be mediated by the degree of child involvement in Special Olympics. To increase the inferential nature of the analysis and intraindividual control, I used a longitudinal design, testing parents at two time intervals, which were, on average, 42 months apart. Mothers' age and child's diagnosis were controlled at every step. Also, results were obtained after controlling for the variance accounted for by initial parent functioning at Time 1. Thus, any relation linking maladaptive behavior at Time 1 to parent functioning at Time 2 did so after the effect of the parent functioning at Time 1 was controlled. Similarly, any relations found between Special Olympics involvement at Time 1 and parent functioning at Time 2 could not be accounted for by parents' baseline levels of parenting distress at Time 1. My main goal in this study was to better understand the role that involvement in Special Olympics plays for parents of athletes, and the longitudinal design and mediation model were useful to this end.

The first hypothesis was that a child's social maladjustment would be a significant predictor of maternal stress, which was largely supported across all but one of the Parenting Stress Index:3 subscales (Problems With Attachment). This finding is consistent with results of relations between overall child behavior problems and maternal stress using the Parenting Stress Index:3 with mothers of children and adolescents with Down syndrome (Hodapp, Ricci, Ly, \& Fidler, 2003). The current results also mirror findings of relations between child problem behavior and other measures of stress with young children who have intellectual disabilities (Fidler, Hodapp, \& Dykens, 2000; Hodapp et al., 1997) and from studies in which investigators directly measured parenting competence (Haldy \& Hanzlik, 1990; Hassall, Rose, \& McDonald, 2005) and depression (Seltzer, Greenberg, \& Krauss, 1995).

The results supported my second hypothesis (i.e., that children's socially maladaptive behavior at Time 1 would be related to their degree of involvement in Special Olympics). Athletes' levels of social competence have been positively correlated with the number of years in Special Olympics (Dykens \& Cohen, 1996) and with the number of competitions they experience (Weiss et al., 2003). In addition, Dykens and Cohen (1996) found that individuals who participated in Special Olympics had greater social competence and adaptive behaviors than did a group of nonparticipating peers matched on IQ, age, gender, and socioeconomic status. Given that a person's functioning has a bidirectional influence with their environment (Bandura, 1989), it is likely that maladaptive behavior can have an impact on involvement in Special Olympics and that Special Olympics can influence an athlete's conduct.

Results of this study also supported the third hypothesis, that a child's involvement in Special Olympics would be inversely related to problems with maternal functioning. Involvement in Special Olympics was a significant predictor of all five measures of maternal functioning. The greater a child's involvement in Special Olympics at Time 1 , the fewer problems with maternal functioning at Time 2, after controlling for mothers' baseline levels and the child's degree of maladaptive behavior at Time 1. Many parents of Special Olympics athletes have noted that involving their child in the organization can have multiple benefits for the child and the family (Klein et al., 1993). Because in the present analysis I used a summary variable to reflect involvement, the determination of which component of Special Olympics matters most for parents is not possible, only that having a child involved in this program is relevant to mothers' experience of parenting. More generally, parents have articulated the need for formal supports in the community for their adult child with intellectual disabilities (Freedman, Griffiths, Krauss, \& Seltzer, 1999; Heller \& Factor, 1993) and have stressed the importance of creating opportunities for children with intellectual disabilities to make friends and participate in social activities (Minnes \& Woodford, 2005). Parents who involve their children in Special Olympics may feel that the organization helps fulfill such a role.

The final hypothesis was that involvement in Special Olympics would mediate the relation between a child's social maladaptive behavior and parent outcome. Results indicated that Special Olympics was a full mediator between stressor and maternal role restriction and depression and a partial mediator between stressor and maternal problems with competence. There are several reasons this involvement may buffer the impact of stressors on parent functioning, based on theories of stress, coping, and family ecology (Crnic et al., 1983). First, researchers have shown that meeting the service needs of adults with intellectual dis- 
abilities is associated with an increase in caregiver well-being and a decrease in caregiver depression (Minnes \& Woodford, 2005; Seltzer \& Krauss, 1989), and Special Olympics may satisfy part of the child's need for social and sports opportunities. Second, it is possible that involvement in Special Olympics may provide parents with an opportunity to meet other parents and establish a social support network, which has been found to predict decreased stress and better adjustment for parents of children with disabilities (Crnic et al., 1983; Friedrich, Wilturner, \& Cohen, 1985). Third, watching one's child accomplish new tasks in Special Olympics may help to foster positive parent attitudes towards the child, and a positive perspective has been linked to lower levels of parent stress (Crnic et al., 1983; Friedrich et al., 1985). Finally, Special Olympics may provide parents with temporary respite from the day to day challenges of caregiving, including dealing with problem behavior, which has been associated with feelings of role restriction in mothers of a young child with intellectual disabilities (Roach, Orsmond, \& Barrett, 1999).

While testing the mediation hypothesis, I found a noticeable increase in the predictive strength of child diagnosis on maternal role restriction and depression. Suppression effects may have occurred during the multiple regressions. A suppressor variable increases the validity of a predictor by its inclusion in a regression equation by accounting for error variance of the predictor (Conger, 1974), often evidenced when the predictor's near zero beta weight increases as a result of the inclusion (Smith, Ager, \& Williams, 1992). Univariate comparisons between children with Down syndrome and those with other etiologies revealed no significant differences in involvement in Special Olympics or parent functioning, suggesting that the relation between child diagnosis and these other variables could not be revealed without controlling for additional error variance. At the same time, the complex results of the mediation model suggest that involvement in Special Olympics can intercede in the relation among social maladjustment and role restriction, depression, and problems with competence, but that it is critical to take into account other factors (i.e., etiology of intellectual disabilities). It is possible that the impact of Special Olympics on parent functioning may differ depending on characteristics of the child, such as personality or behavioral phenotype.
It is important to recognize a number of limitations of this research. Overall, participants did not exhibit a significant degree of social maladjustment compared to the ABS-RC2 norms, with most being in the "average" range. Results may not, therefore, generalize to mothers of individuals with intellectual disabilities who may need formal supports the most, namely, those with children who have very high levels of problem behavior. It is unclear to what extent Special Olympics routinely supports people with clinically significant levels of socially maladaptive behavior, and future researchers could examine the role of physical activity programs for people with intellectual disabilities and mental health problems or significant challenging behaviors. This study did, however, include mothers with clinically significant levels of stress, and results suggest that Special Olympics includes families who have high levels of need.

There was a $34 \%$ attrition rate in this study. Mothers with children who were involved in Special Olympics for longer and had acquired more medals and ribbons at Time 1 were more likely to remain in the study compared to mothers with children who were less involved in Special Olympics. This difference may be an indication of selection bias, as responders were more involved at Time 1 than nonresponders and may have initially been more successful. However, there were no significant differences in the number of competitions experienced between responders and nonresponders. More importantly, an examination of child maladaptive behavior at Time 1 and parent experiences at Time 1 revealed no differences between responders and nonresponders in either the stressor or outcome variables.

Mothers who remained in the study also tended to be more educated than those who only participated at Time 1 and may have had better financial status than corresponding mothers. These biases have been noted as common challenges to longitudinal research (Farrington, 1991) and may have been partly the result of using correspondence by mail as the method of data collection. An alternative for future researchers would be to use telephone surveys that do not require reading or writing skills.

Mothers were, on average, between 50 and 60 years of age during the time of the study, and life stresses associated with this age segment were not included as either a stressor or mediator in the analyses. Significant stressors, such as loss of a 
spouse, health problems, or transitions from work to retirement, may be highly relevant to mothers at this point in their lives. Although results of the present study demonstrate that a communitybased sports program for their child is related to the parenting experience, it is beyond the scope in this study to propose a complete model of maternal functioning. Formal supports are only one part of a comprehensive model of stress and coping; a host of additional variables are critical to developing an understanding of the experience of parenting an adult child with intellectual disabilities.

\section{Summary}

The present results are important, despite the limitations discussed above. This is the first study in which the link between child involvement in Special Olympics and parent outcome was quantitatively examined. Results that demonstrate a negative correlation between involvement in Special Olympics and parent distress and positive correlations between Special Olympics and social competence and self-esteem suggest that there may be some quantifiable merit to Special Olympics programming (Dykens \& Cohen, 1996; Weiss et al., 2003). A beneficial reciprocal relationship may exist between a positive parent experience and involvement in Special Olympics, and there are data to suggest that some aspects of Special Olympics play a mediating role as a formal support for mothers. Physical activity programming can be integrated as part of the larger support system for individuals with intellectual disabilities, and researchers are encouraged to focus on the aspects of physical activity programming that may benefit both the athlete and the family unit.

\section{References}

Abidin, R. R. (1995). Parenting Stress Index manual (3rd ed.). New York: Psychological Assessment Resources.

Addington, D., Addington, J. M., \& Ens, I. (1993). Mentally retarded patients on general hospital psychiatric units. Canadian Journal of Psychiatry, 38, 134-136.

Baker, B. L., Blacher, J., \& Olsson, B. (2005). Preschool children with and without developmental delay: Behaviour problems, parents' optimism and well-being. Journal of Intellectual Disability Research, 49, 575-590.
Bandura, A. (1989). Social cognitive theory. In R. Vasta (Ed.), Annals of child development. Six theories of child development. (pp. 1-60). Greenwich, CT: JAI Press.

Baron, R. M., \& Kenny, D. A. (1986). The moderator-mediator variable distinction in socialpsychological research: Conceptual, strategic, and statistical considerations. Journal of Personality and Social Psychology, 51, 1173-1182.

Bristol, M. M. (1987). The home care of children with developmental disabilities: Empirical support for a model of successful family coping with stress. In S. Landesman, P. M. Vietze, \& M. J. Begab (Eds.), Living environments and mental retardation (pp. 401-422). Washington, DC: American Association on Mental Retardation.

Bristol, M. M., Gallagher, J. J., \& Schopler, E. (1988). Mothers and fathers of young developmentally disabled and nondisabled boys: Adaptation and spousal support. Developmental Psychology, 24, 441-451.

Castagno, K. S. (2001). Special Olympics unified sports: Changes in male athletes during a basketball season. Adapted Physical Activity Quarterly, 18, 193-206.

Coakley, J. (1987). Children and the sport socialization process. In D. Gould \& M. R. Weiss (Eds.), Advances in pediatric sport sciences: Vol. 2. Behavioral issues. Champaign, IL: Human Kinetics.

Conger, A. J. (1974). A revised definition for suppressor variables: A guide to their identification and interpretation. Educational and Psychological Measurement, 34, 35-46.

Crnic, K. A., Friedrich, W. N., \& Greenberg, M. T. (1983). Adaptation of families with mentally retarded children: A model of stress, coping, and family ecology. American Journal on Mental Deficiency, 88, 125-138.

Dykens, E. M., \& Cohen, D. J. (1996). Effects of Special Olympics international on social competence in persons with mental retardation. Journal of the American Academy of Child and Adolescent Psychiatry, 35, 223-229.

Farrington, D. (1991). Longitudinal research strategies: Advantages, problems, and prospects. Journal of the American Academy of Child and Adolescent Psychiatry, 30, 369-374.

Fidler, D. J., Hodapp, R. M., \& Dykens, E. M. (2000). Stress in families of young children with Down syndrome, Williams syndrome, 
and Smith-Magenis syndrome. Early Education and Development, 11, 395-406.

Flaherty, E. M., \& Glidden, L. M. (2000). Positive adjustment in parents rearing children with Down syndrome. Early Education and Development, 11, 407-422.

Freedman, R. I., Griffiths, D., Krauss, M. W., \& Seltzer, M. M. (1999). Patterns of respite use by aging mothers of adults with mental retardation. Mental Retardation, 37, 93-103.

Friedrich, W. N., Greenberg, M. T., \& Crnic, K. (1983). A short-form of the questionnaire on resources and stress. American Journal on Mental Deficiency, 88, 41-48.

Friedrich, W. N., Wilturner, L. T., \& Cohen, D. S. (1985). Coping resources and parenting mentally retarded children. American Journal on Mental Deficiency, 90, 130-139.

Gencoz, F. (1997). The effects of basketball training on the maladaptive behaviors of trainable mentally retarded children. Research in Developmental Disabilities, 18, 1-10.

Gibbons, S. L., \& Bushakra, F. B. (1989). Effects of Special Olympics participation on the perceived competence and social acceptance of mentally retarded children. Adapted Physical Activity Quarterly, 6, 40-51.

Glidden, L. M., \& Schoolcraft, S. A. (2003). Depression: Its trajectory and correlates in mothers rearing children with intellectual disability. Journal of Intellectual Disability Research, 47, 250-263.

Haldy, M. B., \& Hanzlik, J. R. (1990). A comparison of perceived competence in child rearing between mothers of children with Down syndrome and mothers of children without delays. Education and Training in Mental Retardation, 25, 132-141.

Hanson, M. J., \& Hanline, M. F. (1990). Parenting a child with a disability: A longitudinal study of parent stress and adaptation. Journal of Early Intervention, 14, 234-248.

Hassall, R., \& Rose, J. (2005). Parent cognitions and adaptation to the demands of caring for a child with an intellectual disability: A review of the literature and implications for clinical interventions. Behavioural and Cognitive Psychotherapy, 33, 71-88.

Hassall, R., Rose, J., \& McDonald, J. (2005). Parenting stress in mothers of children with an intellectual disability: The effects of parent cognitions in relation to child characteristics and family support. Journal of Intellectual Disability Research, 49, 405-418.

Hauser-Cram, P., Warfield, M. E., Shonkoff, J. P., \& Krauss, M. W. (2001). Children with disabilities: A longitudinal study of child development and parent well being. Monographs of the Society for Research in Child Development, 66(3), 1-131.

Heller, T., \& Factor, A. R. (1993). Support systems, well-being, and placement decision making among older parents and their adult children with developmental disabilities. In E. Sutton, A. R. Factor, B. A. Hawkins, T. Heller, \& G. B. Seltzer (Eds.), Older adults with developmental disabilities: Optimizing choice and change (pp. 107-122). Baltimore: Brookes.

Hodapp, R. M., Dykens, E. M., \& Masino, L. L. (1997). Families of children with Prader Willi syndrome: Stress-support and relations to child characteristics. Journal of Autism and Developmental Disorders, 27, 11-24.

Hodapp, R. M., Ricci, L. A., Ly, T. M., \& Fidler, D. J. (2003). The effects of the child with Down syndrome on maternal stress. British Journal of Developmental Psychology, 21, 137151.

Hurley, A. D., Folstein, M., \& Lam, N. (2003). Patients with and without intellectual disability seeking outpatient psychiatric services: Diagnoses and prescribing pattern. Journal of Intellectual Disability Research, 47, 39-50.

Jones, J., \& Passey, J. (2005). Family adaptation, coping and resources: Parents of children with developmental disabilities and behaviour problems. Journal on Developmental Disabilities, 11, 31-46.

Kaufman, A. S., \& Kaufman, N. L. (1990). Kaufman Brief Intelligence Test manual. Circle Pines, MN: American Guidance Service.

Kazak, A. E. (1987). Families with disabled children: Stress and social networks in three samples. Journal of Abnormal Child Psychology, 15, 137-146.

Keller, D., \& Honig, A. S. (2004). Maternal and paternal stress in families with school aged children with disabilities. American Journal of Orthopsychiatry, 74, 337-348.

Klein, T., Gilman, E., \& Zigler, E. (1993). Special Olympics: An evaluation by professionals and parents. Mental Retardation, 31, 15-23.

Krauss, M. W. (1993). Child-related and parenting stress: Similarities and differences between mothers and fathers of children with disabil- 
ities. American Journal on Mental Retardation, 97, 393-404.

Margalit, M., Shulman, S., \& Stuchinger, N. (1989). Behavior disorders and mental retardation: The family systems perspective. $R e-$ search in Developmental Disabilities, 10, 315326.

Minnes, P. M. (1988). Family resources and stress associated with having a mentally retarded child. American Journal on Mental Retardation, 93, 184-192.

Minnes, P., \& Woodford, L. (2005). Well-being in aging parents caring for an adult with a developmental disability. Journal on Developmental Disabilities, 11, 47-66.

Nihira, K., Leland, H., \& Lambert, N. (1993). Adaptive Behavior Scales-Residential and Community Edition: Examiner's manual. (3rd ed.). Austin, TX: Pro-Ed.

Orsmond, G. I., Seltzer, M. M., Krauss, M. W., \& Hong, J. (2003). Behavior problems in adults with mental retardation and maternal well-being: Examination of the direction of effects. American Journal on Mental Retardation, 108, 257-271.

Pakenham, K. I., Sofronoff, K., \& Samios, C. (2004). Finding meaning in parenting a child with Asperger syndrome: Correlates of sense making and benefit finding. Research in Developmental Disabilities, 25, 245-264.

Perry, A. (2005). A model of stress in families of children with developmental disabilities: Clinical and research applications. Journal on Developmental Disabilities, 11, 1-16.

Preacher, K. J., \& Leonardelli, G. J. (2001). Calculation for the Sobel Test. An interactive calculation tool for mediation tests. Retrieved June 15, 2004, from http://www.unc.edu/ $\sim$ preacher/sobel/sobel.htm

Ricci, L. A., \& Hodapp, R. M. (2003). Fathers of children with Down's syndrome versus other types of intellectual disability: Perceptions, stress and involvement. Journal of Intellectual Disability Research, 47, 273-284.

Riggen, K., \& Ulrich, D. (1993). The effects of sport participation on individuals with mental retardation. Adapted Physical Activity Quarterly, 10, 42-51.

Roach, M. A., Orsmond, G. I., \& Barratt, M. S.
(1999). Mothers and fathers of children with Down syndrome: Parent stress and involvement in childcare. American Journal on Mental Retardation, 104, 422-436.

Saloviita, T., Italinna, M., \& Leinonen, E. (2003). Explaining the parent stress of fathers and mothers caring for a child with intellectual disability: A double ABCX model. Journal of Intellectual Disability Research, 47, 300-312.

Seltzer, M. M., Greenberg, J. S., \& Krauss, M. W. (1995). A comparison of coping strategies of aging mothers of adults with mental illness or mental retardation. Psychology of Aging, 10, 64-75.

Seltzer, M. M., \& Krauss, M. W. (1989). Aging parents with mentally retarded children: Family risk factors and sources of support. American Journal on Mental Retardation, 94, 303312.

Smith, R. L., Ager, J. W., Jr., \& Williams, D. L. (1992). Suppressor variables in multiple regression/correlation. Educational and Psychological Measurement, 52, 17-29.

Weiss, J. A., Diamond, T., Demark, J., \& Lovald, B. (2003). Involvement in Special Olympics and its relations to self-concept and actual competency in participants with developmental disabilities. Research in Developmental Disabilities, 24, 281-305.

Received 5/23/05, accepted 1/21/08.

Editor-in-charge: Elisabeth Dykens

This research was supported by a research grant from Special Olympics Canada and a postdoctoral fellowship from the Canadian Institutes of Health Research. The author acknowledges Terry Diamond for her substantial contributions to the first phase of this research, Adrienne Perry, April Sullivan, and Carmen Bewell for their helpful comments, and Elisabeth Dykens and the anonymous reviewers for the thorough and constructive reviews. Most important, a special thank you to the many families in Special Olympics Ontario for their participation. Correspondence regarding this article should be sent to Jonathan A. Weiss, Centre for Addiction for Mental Health, Dual Diagnosis Program, Toronto, Ontario M6J $1 \mathrm{H} 4$. Canada. E-mail: Jonathan_Weiss@camh.net 